\title{
A case of malignant hyperthermia during anesthesia induction with sevoflurane
} -A case report-

\author{
Yoon Sook Lee, Woon Young Kim, Se Hwa Lee, Sung Moon Baek, Se Jin Ok, Jae Hwan Kim, and \\ Young Cheol Park
}

Department of Anesthesiology and Pain Medicine, Korea University Ansan Hospital, Ansan, Korea

We experienced a case of malignant hyperthermia $(\mathrm{MH})$ in 6-year-old boy during anesthesia induction for strabismus surgery. It has been generally reported that sevoflurane can induce the delayed onset of $\mathrm{MH}$ in the absence of succinylcholine. Our case of $\mathrm{MH}$ was elicited after about 2-3 min of sevoflurane administration with $\mathrm{N}_{2} \mathrm{O}, \mathrm{O}_{2}$ and rocuronium. However, we successfully treated the patient by early recognition of his condition and administering symptomatic treatment and dantrolene. (Korean J Anesthesiol 2010; 59: S6-S8)

Key Words: Dantrolene, Malignant hyperthermia, Sevoflurane.

Malignant hyperthermia ( $\mathrm{MH})$ is a chain reaction of symptoms that are triggered in susceptible individuals by commonly used inhalation agents such as halothane, enflurane, isoflurane and sevoflurane and also muscle relaxants such as succinylcholine. The symptoms of MH include a greatly increased body metabolism, high fever and muscle rigidity. It is known that sevoflurane and desflurane are less potent triggers that produce a more gradual onset of $\mathrm{MH}[1,2]$. Yet we encountered a case of MH during anesthetic induction with sevoflurane, and the patient was successfully treated by early recognition of his condition and administering symptomatic treatment and dantrolene.

\section{Case Report}

A 6-year-old, $25 \mathrm{~kg}$ boy was scheduled for strabismus surgery in both eyes. Neither the patient nor his family had any history of neuromuscular disease or a special family history. He had not previously received general anesthesia. The preoperative laboratory examinations were within the normal values. The patient received atropine $0.25 \mathrm{mg}$ IM for premedication 30 min before induction. The preoperative vital signs were blood pressure: $90 / 50 \mathrm{mmHg}$, heart rate: 92 beats/min, respiratory rate: $24 / \mathrm{min}$ and axillary temperature: $36.4^{\circ} \mathrm{C}$. The patient received ketamine $50 \mathrm{mg}$ IV for sedation before induction in the

Received: February 10, 2010. Revised: 1st, March 2, 2010; 2nd, April 13, 2010. Accepted: June 10, 2010.

Corresponding author: Woon Young Kim, M.D., Department of Anesthesiology and Pain Medicine, Korea University Ansan Hospital, 516, Gojan-dong, Danwon-gu, Ansan 425-707, Korea. Tel: 82-31-412-5291, Fax: 82-31-412-5294, E-mail: ckssis@korea.ac.kr

(c) This is an open-access article distributed under the terms of the Creative Commons Attribution Non-Commercial License (http:// creativecommons.org/licenses/by-nc/3.0/), which permits unrestricted non-commercial use, distribution, and reproduction in any medium, provided the original work is properly cited. 
waiting room.

Anesthesia was induced with sevoflurane 2.5 vol\% by mask ventilation in a mixture of nitrous oxide and oxygen $\left(\mathrm{FiO}_{2}\right.$ 0.5). Fifteen mg of rocuronium bromide was injected during induction. About $2 \mathrm{~min}$ after injection of rocuronium bromide, a size 5.0 cuffed endotracheal tube was inserted without any difficulty under direct laryngoscopy. Then $1 \mathrm{~min}$ after intubation, the heart rate of patient was increased from 160 to 195 beats/min. At first, the tachycardia was considered to be due to stimulation by the tracheal intubation, but the end tidal carbon dioxide concentration $\left(\mathrm{ETCO}_{2}\right)$ was concurrently increased from 35 to $65 \mathrm{mmHg}$ within $5 \mathrm{~min}$. The oral temperature was increased to $38.9^{\circ} \mathrm{C}$ within $5 \mathrm{~min}$ after induction. No significant changes in the muscle tone and skin appearance were noted. We suspected $\mathrm{MH}$, so we stopped using sevoflurane and $\mathrm{N}_{2} \mathrm{O}$. The patient was hyperventilated with $100 \% \mathrm{O}_{2}$ through a new anesthetic circuit, and consequently the $\mathrm{ETCO}_{2}$ was decreased to $45 \mathrm{mmHg}$. The patient was administered midazolam $1 \mathrm{mg}$ and sufentanyl $15 \mu \mathrm{g}$ intravenously for sedation after discontinuing the sevoflurane and we started propofol infusion as maintenance because propofol is known to be a safe anesthetic agent in patients with $\mathrm{MH}$.

For decreasing the body temperature, active cooling was immediately initiated by ice water massage and applying ice packs on the chest, back and axillary area. Arterial cannulation was done to continuously monitor the blood pressure and for the arterial blood gas analysis. This was done via external jugular cannulation for rapid infusion of cold IV fluid and central administration of drugs for resuscitation if it was need, and we placed a Foley catheter for checking the hour urine output. The arterial blood gas analysis was $\mathrm{pH}$ : 7.294, $\mathrm{PaCO}_{2}$ : $41.2 \mathrm{mmHg}, \mathrm{PaO}_{2}: 435.2 \mathrm{mmHg}$ and the base excess: -10.1 $\mathrm{mM} / \mathrm{L}$. The myoglobin in the serum was normal and the urine was negative for myoglobin. The creatine phosphokinase and potassium levels in the serum were normal. We administered $8.4 \%$ sodium bicarbonate $10 \mathrm{ml}$ for correcting the acidosis. Thirty minutes min after anesthetic induction, the patient showed an oral temperature of $38^{\circ} \mathrm{C}$, a pulse of 160 beats $/ \mathrm{min}$, a blood pressure of 140/70 and we detected newly occurring ventricular premature beats $(4-5 / \mathrm{min})$ on the echocardiogram. So, we decided to stop the general anesthesia and surgery and administer dantrolene. But we didn't have dantrolene, so we requested dantrolene from the Korea orphan drug center.

Approximately $90 \mathrm{~min}$ after the onset of $\mathrm{MH}$, the patient recovered consciousness and the tracheal tube was extubated. The patient was transferred to the intensive care unit for further observation. About $120 \mathrm{~min}$ after onset of $\mathrm{MH}$, we received the dantrolene. The patient showed an oral temperature of $37.5^{\circ} \mathrm{C}$, a heart rate of 140 beats/min and a blood pressure of 140/80
$\mathrm{mmHg}$, and he maintained the ventricular premature beats $(4-5 / \mathrm{min})$. The arterial blood gas analysis showed a $\mathrm{pH}$ of 7.390 , a $\mathrm{PaCO}_{2}$ of $38.0 \mathrm{mmHg}$, a $\mathrm{PaO}_{2}$ of $89.5 \mathrm{mmHg}$ and a base excess of $-2.5 \mathrm{mM} / \mathrm{L}$.

Dantrolene $25 \mathrm{mg}$ was administered intravenously. Thereafter, the arrhythmia disappeared, and the patient maintained an oral temperature of $36.5-37.4^{\circ} \mathrm{C}$ and a normal blood pressure and heart rate. But about $2 \mathrm{~h}$ after the administration of dantrolene, the patient again showed arrhythmia (ventricular premature beats) and an increased oral temperature of $38^{\circ} \mathrm{C}$, a blood pressure of 130/100 $\mathrm{mmHg}$ and a heart rate of 130 beats $/ \mathrm{min}$. Dantrolene $25 \mathrm{mg}$ was administered again. After the second administration of dantrolene, the arrhythmia, oral temperature, heart rate and blood pressure were all normalized, and the laboratory data and arterial blood gas analysis were normalized 2 days after anesthesia induction.

Further evaluations for MH were refused by the patient's parents. The patient was discharged from the hospital four days after the onset of MH without any problem.

\section{Discussion}

Many early signs of a MH episode can present in various ways and MH may be confused with other medical conditions such as an insufficient depth of anesthesia, hypoxia, hypercarbia, thyrotoxicosis, pheochromocytoma and neuroleptic malignant syndrome $[3,4]$. A clinical grading scale helps to establish the likelihood of MH in specific problematic cases [5]. It is based on weighted scores for muscle tone, muscle breakdown, acid-base parameters, temperature, tachycardia or other arrhythmias, and the response to dantrolene. We were able to diagnose $\mathrm{MH}$ on the basis of the clinical symptoms and the clinical grading scale by Larach et al. [5]. According to this clinical grading scale, when the raw score range is $35-48$, the $\mathrm{MH}$ rank is 5 and the likelihood of MH is high. The patient in this case had a score of 43 . The patient in this case received the score of 43 because the $\mathrm{PETCO}_{2}$ was $>55 \mathrm{mmHg}$ with appropriately controlled ventilation (15 points), there was an inappropriately rapid increase in temperature (15 points), inappropriate sinus tachycardia (3 points) and an arterial base excess more negative than $-8 \mathrm{mEq} / \mathrm{L}$ (10 points).

In this case, we used ketamine, sevoflurane, $\mathrm{N}_{2} \mathrm{O}$ and rocuronium bromide during induction. Ketamine and $\mathrm{N}_{2} \mathrm{O}$ are not triggers for $\mathrm{MH}$ [6-8] and rocuronium bromide, which is a nondepolarizing muscle relaxant, is also safe for $\mathrm{MH}$.

Since Shulman et al. [1] first reported that sevoflurane triggers $\mathrm{MH}$ in MH-susceptible swine, there have been some reports of $\mathrm{MH}$ during sevoflurane anesthesia in human. Generally, sevoflurane and desflurane have been reported to be less potent triggers, they produce a more gradual onset of $\mathrm{MH}[1,2]$ and the 
onset of MH with sevoflurane in humans has been reported to occur both at an early period and after prolonged anesthesia. We encountered a case of $\mathrm{MH}$ that developed during anesthesia induction with sevoflurane. It took just about 5 minutes for eliciting the symptoms of $\mathrm{MH}$.

Kinouchi et al. [9] reported $\mathrm{MH}$ emerged about 30 minutes after anesthetic induction with sevoflurane in 4-year-old girl who was without a family history of $\mathrm{MH}$ and the preoperative laboratory studies did not suggest she was susceptible to $\mathrm{MH}$. Jonassen et al. [10] reported that MH emerged about 20 minutes after anesthetic induction with sevoflurane in a 56 -year-old man who was undergoing cardiopulmonary bypass and moderate hypothermia. Cheong et al. [11] reported that MH emerged about 150 minutes after general anesthesia with sevoflurane in a 24-year-old man who was undergoing bilateral sagittal split ramus osteotomy.

As compared with the other case reports, our patient's $\mathrm{ETCO}_{2}$ and body temperature were increased simultaneously within 5 minutes after anesthetic induction with sevoflurane. This is the earliest onset among the case reports of $\mathrm{MH}$ reported until now.

We know that the time of onset of a fulminant episode of $\mathrm{MH}$ is unpredictable, and it can vary from within minutes to within several hours of induction, and the fulminant MH episodes are apparently the result of a rapid, sustained rise in myoplasmic $\mathrm{Ca}^{2+}$. However, we could not determine the reason for the rapid onset of $\mathrm{MH}$ in this case.

During the preoperative evaluation, our attention was drawn to the patient' strabismus, and strabismus has been observed in $\mathrm{MH}$ susceptible patients. However, neither the family history nor the preoperative laboratory studies suggested the patient was susceptible to $\mathrm{MH}$. There is no convenient minimally invasive laboratory test available for MH susceptibility. The halothane and caffeine contracture tests are bioassays and they currently remain the most reliable indicators, but they are not generally used in our country, and so a diagnostic contracture test was not performed.

This case report demonstrates that sevoflurane can trigger $\mathrm{MH}$ within few minutes after exposure and so the patients who are susceptible to $\mathrm{MH}$ must be carefully monitored even during anesthetic induction.

\section{References}

1. Shulman M, Braverman B, Ivankovich AD, Gronert G. Sevoflurane triggers malignant hyperthermia in swine. Anesthesiology 1981; 54: 259-60.

2. Allen GC, Brubaker CL. Human malignant hyperthermia associated with desflurane anesthesia. Anesth Analg 1998; 86: 1328-31.

3. Rosenberg H. Clinical presentation of malignant hyperthermia. Br J Anaesth 1988; 60: 268-73.

4. Britt BA. Malignant hyperthermia. Can Anaesth Soc J 1985; 32: 666 78.

5. Larach MG, Localio AR, Allen GC, Denborough MA, Ellis FR, Gronert GA, et al. A clinical grading scale to predict malignant hyperthermia susceptibility. Anesthesiology 1994; 80: 771-9.

6. Dershwitz M, Sréter FA, Ryan JF. Ketamine does not trigger malignant hyperthermia in susceptible swine. Anesth Analg 1989; 69: 501-3.

7. Gronert GA. Malignant hyperthermia. Anesthesiology 1980; 53: 395-423.

8. Gronert GA, Milde JH. Hyperbaric nitrous oxide and malignant hyperpyrexia. Br J Anaesth 1981; 53: 1238.

9. Kinouchi K, Okawa M, Fukumitsu K, Tachibana K, Kitamura S, Taniguchi A. Two pediatric cases of malignant hyperthermia caused by sevoflurane. Masui 2001; 50: 1232-5.

10. Jonassen AA, Petersen AJ, Mohr S, Andersson C, Skattum J, Kvernebo K, et al. Sevoflurane-induced malignant hyperthermia during cardiopulmonary bypass and moderate hypothermia. Acta Anaesthesiol Scand 2004; 48: 1062-5.

11. Cheong YK, Jeon CY, Lee C, Song YK, Kim TY, Choi DH. A case of malignant hyperthermia during general anesthesia with sevoflurane. Korean J Anesthesiol 2004; 47: 449-53. 